\title{
Timing of successful settlement: demonstration of a recruitment window in the barnacle Semibalanus balanoides
}

\author{
Jesús Pineda $^{1, *}$, Victoria Starczak ${ }^{1}$, Todd A. Stueckle ${ }^{2}$ \\ ${ }^{1}$ Biology Department, Woods Hole Oceanographic Institution, Woods Hole, Massachusetts 02543, USA \\ ${ }^{2}$ Present address: PO Box 6057, Department of Biology, West Virginia University, Morgantown, West Virginia 26506, USA
}

\begin{abstract}
Recruitment is a key factor in benthic population dynamics, and spatial and temporal processes that affect settlement may determine recruitment; however, temporal processes are not well understood. We tested whether the date that recruits settle is a random sample within the settlement season by measuring daily settlement of the barnacle Semibalanus balanoides throughout the entire settlement season. A total of 2721 barnacle larvae settled during $89 \mathrm{~d}$ on 12 quadrats. Individual settlers were tracked to reproductive age (11 mo after settlement); only 8 survived to reproduction. Survivors settled within a narrow $21 \mathrm{~d}$ recruitment window, a period shorter than expected by chance. The concept of a recruitment window has broad implications in studying benthic recruitment and population dynamics. Focus on the recruitment window when it is narrow could simplify the study of recruitment, since fewer factors would have to be considered.
\end{abstract}

KEY WORDS: Recruitment $\cdot$ Settlement $\cdot$ Intertidal ecology $\cdot$ Barnacle

\section{INTRODUCTION}

Knowledge of the determinants of recruitment is one of the most important goals in marine benthic population dynamics. Recruitment is the survival of individuals after an arbitrary period of time, and is a partial function of settlement rate (e.g. Hatton 1938, Bertness et al. 1992) which, in sessile invertebrates, is the rate at which larvae attach permanently to the substrate (e.g. Connell 1985). Individuals that recruit are a subset of those individuals that settle. Although investigations on the role of larval transport and nearshore larval abundance in successful recruitment are important (e.g. Underwood \& Keough 2000), not all larvae that disperse and settle will recruit and survive to reproduction (e.g. Bhaud 1998). Thus, if many larvae that disperse and settle do not survive to reproduction, then the benefits of studying larval transport and settlement in order to understand population connectivity are arguable, since post-settlement mortality would prevent many settlers from joining the local reproductive pool. Sessile invertebrates and fishes suffer extremely high post-settlement mortality through biotic and abiotic factors (e.g. Hunt \& Scheibling 1997, Doherty et al. 2004). When the bulk of larvae transported during major settlement events fail to recruit (e.g. Pineda et al. 2002), dispersers constitute a demographic sink rather than a subsidy to subpopulations. A complete determination of 'effective' dispersal requires identifying which settlers survive to reproduction.

Some studies have found that early settlers suffer less mortality than late settlers (Connell 1961, Raimondi 1990), while others have found no monotonic trends within their sampling period (Wethey 1986, Jarrett 2000). Timing of settlement can influence fitness (Pfister 1997) and asynchronous settlement coupled with synchronous mortality at 2 sites may result in differences in recruitment between those sites (Pineda et al. 2002). Daily settlement variability is common (see Pineda 2000 for review), and the settlement season can be long. Seasonal variability in post-settlement mortality has not been studied on a fine temporal scale (e.g. 
daily, Gosselin \& Qian 1997) for a sufficiently long period (i.e. the entire settlement season). Weekly and daily cohorts of the barnacle Semibalanus balanoides were followed for up to 3 mo by Connell (1961) and Wethey (1986). Other studies tracked 3 to 10 daily cohorts for 30 to $60 \mathrm{~d}$ (Raimondi 1990, Gosselin \& Qian 1996, Jarrett 2000, 2003). Hills \& Thomason (2003) followed 2 daily cohorts of $S$. balanoides that settled on suspended panels to maturity, and several daily cohorts of Balanus amphitrite and B. crenatus settling on plates were followed for up to $17 \mathrm{~d}$ by De Wolf (1973). Cohorts of recent Chthamalus fissus settlers sampled every 1 to 3 mo were followed from 4 mo of age to their maximum longevity (about $14 \mathrm{mo}$ ) by Sutherland (1990), and in Chthamalus anisopoma, a species that matures in $6 \mathrm{wk}, 3$ daily cohorts were followed to maturity by Raimondi (1990). The survival to reproduction of daily cohorts settling during the entire settlement season has not been documented.

The temporal pattern of settlement may be important in understanding survival to reproduction. Early survivorship and reproductive success is correlated with birthdate in intertidal, shelf and lake fishes (Schultz 1993, Cargnelli \& Gross 1996, Wright \& Gibb 2005), but the relationship between timing of settlement and recruitment in invertebrates is less apparent. It is not clear whether larvae that settle early or late in the settlement season have an equal probability of reproducing, and whether the fine-scale temporal variability in settlement carries over to recruitment and survival to maturity. How does the daily temporal pattern of settlement, which reflects time-dependent hydrodynamic processes and larval abundance near settlement sites, influence recruitment and survival to reproduction? Have larvae that settle during peak settlement a similar likelihood of recruiting as larvae that settle during periods of low settlement? Are recruits a random sample of settlers? We addressed these questions by following daily individual settlers of Semibalanus balanoides throughout an entire settlement season. Very few settlers survived to reproduction, and those that did so settled within a very narrow time period - 'the recruitment window'. Recruitment windows offer new insights into the relationship between settlement and recruitment, and may simplify the study of recruitment in benthic marine invertebrates.

\section{MATERIALS AND METHODS}

Field observations. Settlement substrates were photographed on the shore off Park Road, Woods Hole, Buzzards Bay, Massachusetts, USA $\left(41.533^{\circ} \mathrm{N}\right.$, $70.671^{\circ} \mathrm{W}$ ) (the same location as 'Gansett Point' in Pineda et al. 2002). The location faces north, is pro- tected from open-ocean swell, and has a semidiurnal tide with a maximum range of about $1.5 \mathrm{~m}$. The substrate is made of large scattered granite boulders (ca. 1 to $2 \mathrm{~m}$ diameter) and cobble and pebbles (ca. 0.1 to $0.2 \mathrm{~m}$ diameter) that sometimes roll. Semibalanus balanoides is the most abundant sessile inhabitant in the upper middle intertidal; other sessile species are rare or absent. Barnacles were removed from 12 quadrats on boulders within the $S$. balanoides vertical zone $1 \mathrm{~d}$ before our first settlement measurements. The quadrats were separated by 2 to $60 \mathrm{~m}$, and their slopes varied from parallel to perpendicular with respect to the sea surface. Each quadrat $\left(2.2 \times 1.4 \mathrm{~cm}^{2}\right)$ was marked in the corners with a small piece of plastic ruler, a bee tag, and a permanent ink mark covered with instant adhesive gel.

From 25 January 2002 until no further settlement was observed (24 April 2002), quadrats were photographed daily with a digital camera (Canon ${ }^{\mathrm{TM}}$ EOS D30 fitted with a $65 \mathrm{~mm} 1-5 \times$ macro lens). After 24 April, photographs were taken at $1 \mathrm{~d}$ to $1 \mathrm{wk}$ intervals. Because of bad weather, daily photographs were not possible on 17 dates during the settlement season. Settlement rate was estimated as the total number of new cyprid larvae attached to the substrate per day in all quadrats.

Recruitment window. Each settled individual was numbered and tracked in the photograph time-series. Cyprids and juveniles missing from photographs were considered dead (detached cyprids apparently do not re-attach: Jarrett 2000). The recruitment window was defined as the date vs. frequency function of settlers that survive to reproduction (time of larval release). Date of reproduction was determined from samples of the Park Road population, and estimated to be early winter (late December to early January). Semibalanus balanoides reproduce in their first year, 11 mo after they settle, in Scotland (Connell 1985). From 19 November 2002 until 7 February 2003, 14 to 35 barnacles that had settled in 2002 were collected every $2 \mathrm{wk}$, and their reproductive stage assessed. Stage 1 barnacles had developing gonads, spent gonads, or eggs that were not fertilized, Stage 2 barnacles contained eggs that were fertilized or developing, and Stage 3 barnacles had well-developed nauplii, near to release. A sharp increase in the proportion of Stage 1 barnacles together with a sharp decrease in Stage 3 individuals on 2 consecutive dates was interpreted as larval release.

Window size ' $d$ ' is defined as the difference (in days) between the date of the earliest and latest settlers that survive to reproduction. We conducted a randomization analysis to test whether observed window size $d$ was smaller than would be expected by chance. A random sample of size equal to the number of observed survivors was drawn (without replacement) from the 


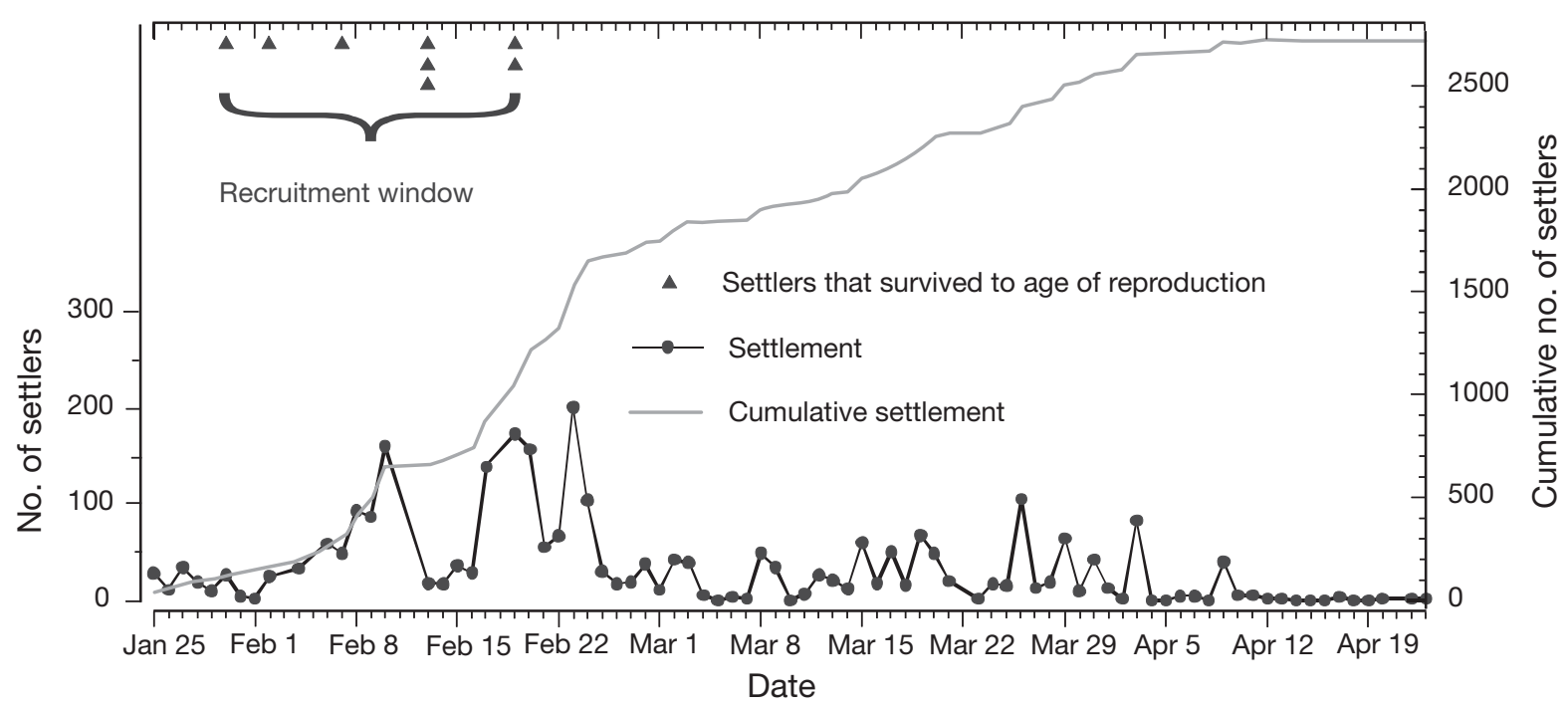

Fig. 1. Semibalanus balanoides. Settlement and recruitment window. Daily settlement and cumulative settlement in 12 quadrats at Park Road, Massachusetts, during the 2002 settlement season. Settlement ended on 23 April. Date of settlement for each of the 8 barnacles that survived to reproductive age is also shown. Date of $50 \%$ cumulative settlement was 22 February

original time-series. Date of settlement was noted, and the difference in days $d$ between the first and last settler calculated; this was repeated 50000 times. The probability of a recruitment window equal or smaller than the observed recruitment window was the number of times $d$ was equal to or smaller than the observed recruitment window size divided by 50000 .

\section{RESULTS}

Settlement was from 25 January to 23 April 2002 and lasted $89 \mathrm{~d}$. Only 8 of the 2741 settlers $(0.29 \%)$ survived to reproductive age. Barnacles that had settled in early 2002 released their larvae around 30 December 2002 to 13 January 2003. (A small proportion of Stage 3 barnacles were collected up to 31 January 2003.) The recruitment window was defined by the 8 settlers that were alive, which had presumably reproduced by mid-January 2003, about 11 mo after settlement (Fig. 1). The recruitment window size $d$ was $21 \mathrm{~d}$, and its temporal position was from 30 January to 19 February. The shape of the window is described by the frequency distribution of recruits over time. The probability of a recruitment window being equal to or smaller than $21 \mathrm{~d}$ was $\mathrm{p}=0.016$ (Fig. 2). Because missing daily sampling dates might have influenced this result, we repeated the analysis with a new time-series, whereby settlement on missing dates was calculated by linear interpolation between dates; this yielded $\mathrm{p}=0.020$. Both results show that a recruitment window of $21 \mathrm{~d}$ is significantly narrower than would be expected by chance.

\section{DISCUSSION}

Barnacles that survived to reproduction settled during a narrow recruitment window, and the recruits were not random representatives of the settlers. Recruitment windows have broad implications for our understanding of marine benthic populations, for the way in which they are studied, and the way in which they are modeled. For example, if narrow recruitment windows are common, studies of larval transport and connectivity should mostly concentrate on determining

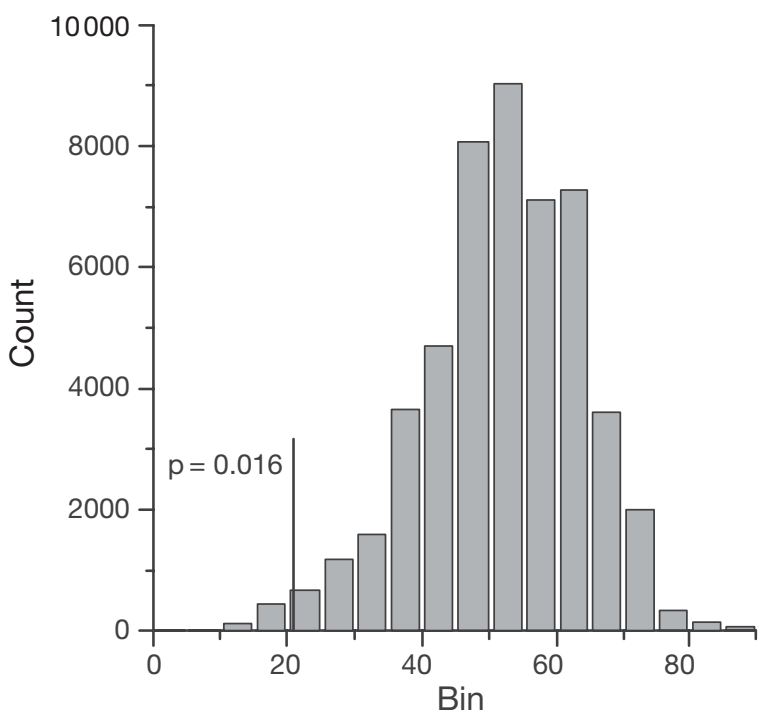

Fig. 2. Semibalanus balanoides. Frequency distribution of window size $d$ from the randomization analysis 
if larval transport coincides with settlers in the recruitment window. Recruitment windows also raise the possibility that a mismatch of a window with settlement peaks would result in recruitment failure, whereas a match should produce a strong year-class.

The concept of a recruitment window in benthic invertebrates may appear analogous to Cushing's match-mismatch hypothesis in fish populations (Cushing 1975), whereby fishes spawn at a fixed time near peaks in phytoplankton abundance. If larval fish occurrence coincides with ideal larval feeding conditions, recruitment is strong, but if ideal feeding conditions are out of phase with occurrence of the larvae, recruitment fails. Cushing's hypothesis, in turn, is analogous to the recruitment failure that occurs when barnacle nauplii fail to develop at the same time as the spring algal bloom (Barnes 1956). The recruitment window in benthic invertebrates differs: it is not an explicative hypothesis, but rather an observable phenomenon and, importantly, is easy to measure in sessile settlers, which can be followed to reproduction.

The broadest temporal aspects of the recruitment window are determined by reproductive schedule and settlement season. What determines the position and shape of the recruitment window within the settlement season? The most parsimonious hypothesis is that the recruitment window is an unbiased sample of settlement, and consequently recruitment is linearly dependent on settlement. This would imply a set of unlikely situations; e.g. that all settlers perform equally, with no effects of maternal phenotype (Marshall et al. 2003) or pelagic experience (Jarrett 2003) on recruitment, that settlers do not modify their settlement environment (e.g. Wethey 1984, Jeffery 2002) in a way that influences recruitment, and that post-settlement mortality is time-independent. Furthermore, our observations have shown that recruitment is not linearly dependent on settlement, but appears to be nonlinear and timedependent. For example, there were no recruits after $50 \%$ cumulative settlement in our study.

If the recruitment window is not an unbiased sample of settlement, then (1) Is it determined by factors largely independent of the settlers? For example, if spatially correlated (coherent) environmental climatic factors determine the limits of the window, variation in the timing of settlement among sites might result in differences in recruitment (e.g. Pineda et al. 2002). (2) Is it determined by factors related to settlers influencing their settlement environment? If settler-habitat factors such as suitable substrate area, gregariousness and repulsion related to high conspecific densities (e.g. Kent et al. 2003) determine the recruitment window, then its position is dependent on the temporal patterns of the settlement rate, and habitat-specific factors such as amount of suitable substrate: for example, early settlers may occupy the best habitat and therefore have higher survival rates (e.g. Connell 1961, Raimondi 1990). (3) Is it determined by the performance of juveniles, a reflection of pelagic larval experience and maternal phenotype? (Jarrett \& Pechenik 1997, Jarrett 2000, 2003, Marshall et al. 2003). What are the relative contributions of environmental vs. settler factors in determining the recruitment window? It is likely that the recruitment window is determined by a combination of all 3 factors, or the beginning or end of the window might be determined by the environment, by the settlers themselves, or a combination. Furthermore, the performance of settlers might be correlated with climatic factors that influence planktonic larval experience.

Identification of the components of post-settlement recruitment has been piecemeal, with studies focusing on one or a few factors at a time (e.g. Gosselin \& Qian 1997, Hunt \& Scheibling 1997), and with almost no studies following settlers to maturity. For example, a multitude of factors influence New England Semibalanus balanoides survival after settlement, including predation, juvenile performance, competition and negative and positive density-dependence, suitable substrate and patchiness, disturbances, temperature and thermal stress, and small-scale hydrodynamics and flow rates. Testing whether each of these factors independently determine recruitment could be fairly straightforward, but testing experimentally or modeling how all factors influence recruitment is daunting, and this is one of the main reasons why full comprehension of recruitment is so difficult. From the piecemeal mechanistic knowledge available, it is difficult to achieve an understanding of local and regional recruitment and recruitment windows. Indeed, because the recruitment window is a statistical distribution most probably influenced by several time dependent processes, a strictly experimental approach addressing each factor might not be the best way to solve the problem. Emphasis on factors that determine the recruitment window as a way to understanding recruitment would complement the single-factor approach, and focusing on the recruitment window when it is narrow could simplify studies of recruitment because fewer factors would need to be investigated.

Consideration of the temporal dependencies of recruitment on settlement (i.e. the relationship between settlement date and recruitment), and the effects of high variability in settlement on recruitment, appears fundamental to understanding the population dynamics of sessile benthic invertebrates.

Acknowledgements. We acknowledge the help of T. Pugh, and the commens and advice of A. Solow and F. Tapia. This work was supported by the US NSF (OCE-9986627 and OCE0083976). 


\section{LITERATURE CITED}

Barnes H (1956) Balanus balanoides (L.) in the Firth of Clyde: the development and annual variation of the larval population, and the causative factors. J Anim Ecol 25:72-84

Bertness MD, Gaines SD, Stephens EG, Yund PO (1992) Components of recruitment in populations of the acorn barnacle Semibalanus balanoides (Linnaeus). J Exp Mar Biol Ecol 156:199-215

Bhaud M (1998) The spreading potential of polychaete larvae does not predict adult distributions; consequences for conditions of recruitment. Hydrobiologia 375/376:35-47

Cargnelli LM, Gross MR (1996) The temporal dimension in fish recruitment: birth date, body size, and size-dependent survival in a sunfish (bluegill: Lepomis macrochirus). Can J Fish Aquat Sci 53:360-367

Connell JH (1961) Effects of competition, predation by Thais lapillus, and other factors on natural populations of the barnacle Balanus balanoides. Ecol Monogr 31:61-104

Connell JH (1985) The consequences of variation in initial settlement vs post-settlement mortality in rocky intertidal communities. J Exp Mar Biol Ecol 93:11-45

Cushing DH (1975) Marine ecology and fisheries. Cambridge University Press, London

De Wolf P (1973) Ecological observations on the mechanisms of dispersal of barnacle larvae during planktonic life and settling. Neth J Sea Res 6:1-129

Doherty PJ, Dufour V, Galzin R, Hixon MA, Meekan MG, Planes S (2004) High mortality during settlement is a population bottleneck for a tropical surgeonfish. Ecology 85: $2422-2428$

Gosselin LA, Qian PY (1996) Early post-settlement mortality of an intertidal barnacle: a critical period for survival. Mar Ecol Prog Ser 135:69-75

Gosselin LA, Qian PY (1997) Juvenile mortality in benthic marine invertebrates. Mar Ecol Prog Ser 146:265-282

Hatton H (1938) Essais de bionomie explicative sur quelques espèces intercotidales d'algues et d'animaux. Ann Inst Océanogr Monaco 17:241-348

Hills JM, Thomason JC (2003) The 'ghost of settlement past' determines mortality and fecundity in the barnacle, Semibalanus balanoides. Oikos 101:529-538

Hunt HL, Scheibling RE (1997) Role of early post-settlement mortality in recruitment of benthic marine invertebrates. Mar Ecol Prog Ser 155:269-301

Jarrett JN (2000) Temporal variation in early mortality of an intertidal barnacle. Mar Ecol Prog Ser 204:305-308

Jarrett JN (2003) Seasonal variation in larval condition and

Editorial responsibility: Otto Kinne (Editor-in-Chief),

Oldendorf/Luhe, Germany postsettlement performance of the barnacle Semibalanus balanoides. Ecology 84:384-390

Jarrett JN, Pechenik JA (1997) Temporal variation in cyprid quality and juvenile growth capacity for an intertidal barnacle. Ecology 78:1262-1265

Jeffery CJ (2002) New settlers and recruits do not enhance settlement of a gregarious intertidal barnacle in New South Wales. J Exp Mar Biol Ecol 275:131-146

Kent A, Hawkins SJ, Doncaster P (2003) Population consequences of mutual attraction between settling and adult barnacles. J Anim Ecol 72:941-952

Marshall DJ, Bolton TF, Keough MJ (2003) Offspring size affects the post-metamorphic performance of a colonial marine invertebrate. Ecology 84:3131-3137

Pfister CA (1997) Demographic consequences of within-year variation in recruitment. Mar Ecol Prog Ser 153:229-238

Pineda J (2000) Linking larval settlement to larval transport: assumptions, potentials, and pitfalls. Oceanogr East Pac 1:84-105

Pineda J, Riebensahm D, Medeiros-Bergen D (2002) Semibalanus balanoides in winter and spring: larval concentration, settlement, and substrate occupancy. Mar Biol 140: 789-800

Raimondi PT (1990) Patterns, mechanisms, consequences of variability in settlement and recruitment of an intertidal barnacle. Ecol Monogr 60:283-309

Schultz ET (1993) The effect of birth date on fitness of female dwarf perch, Micrometrus minimus (Perciformes: Embiotocidae). Evolution 47:520-539

Sutherland JP (1990) Recruitment regulates demographic variation in a tropical intertidal barnacle. Ecology 71: 955-972

Underwood AJ, Keough MJ (2000) Supply-side ecology. The nature and consequences of variation in recruitment of intertidal organisms. In: Bertness MD, Gaines SD, Hay ME (eds) Marine community ecology. Sinauer Associates, Sunderland, MA, p 183-200

Wethey DS (1984) Spatial pattern in barnacle settlement: day to day changes during the settlement season. J Mar Biol Assoc UK 64:687-698

Wethey DS (1986) Local and regional variation in settlement and survival in the littoral barnacle Semibalanus balanoides (L.): patterns and consequences. In: Moore PG, Seed R (eds) The ecology of rocky coasts. Columbia University Press, New York, p 194-202

Wright PJ, Gibb FM (2005) Selection for birth date in North Sea haddock and its relation to maternal age. J Anim Ecol 74:303-312

Submitted: May 10, 2005; Accepted: February 9, 2006

Proofs received from author(s): August 14, 2006 